\title{
CERVICAL CANCER SCREENING IN CHITTAGONG MEDICAL COLLEGE HOSPITAL: BOTTLENECK OF SERVICE DELIVERY SYSTEM OF A REFERRAL CENTER IN BANGLADESH
}

\author{
NASREEN BANU ${ }^{1}$, JANNATUL FERDOUSH ${ }^{2}$, TAHERA BEGUM ${ }^{3}$ \\ ${ }^{1}$ Assistant Professor, Department of Gynaecology \& Obstetrics, Chittagong Medical College Hospital, Chittagong, Bangladesh \\ ${ }^{2}$ Assistant Professor, Department of Gynaecology \& Obstetrics, Chittagong Medical College Hospital, Chittagong, Bangladesh \\ ${ }^{3}$ Assistant Professor, Department of Gynaecology \& Obstetrics, Southern Medical College, Chittagong, Bangladesh
}

\begin{abstract}
Bangladesh is overburdened with cervical cancer. In each year 13,000 new cases enter in this series. Visual inspection of cervix with acetic acid (VIA) is adopted as national cervical cancer (ca cx) screening program, in Bangladesh. Positive VIA, abnormal cytology, positive HPV or suspicious looking cervices are referred for secondary screening (Colposcopy). Chittagong Medical College Hospital (CMCH) acts as a primary screening and secondary referral center. With the aim to identify the weakness of present ca CX screening system one year (April 2013 to March 2014) records were evaluated. A total 1853 VIA \& 714 colposcopy cases were analyzed from records of $\mathrm{CMCH}$, Bangladesh. The age of population range from $16-71$ years and most were between 30-49 years. In primary screening VIA +ve cases were $6 \%(n=120)$. After secondary screening $43.69 \%$ ( $n=312$ ) were identified as abnormal; among those precancerous lesion (CIN) $37.82 \%(n=270)$; ca $c$ x $1.54 \%(n=11)$; suspicious $4.34 \%(n=31)$. Histopathology proven CIN $12.04 \%(n=86)$ \& ca cX $2.10 \%(n=15)$. Cases received treatment (LEEP) were only 09.38\% ( $n=67)$. Finally among total population, 56.30\% ( $n=402)$ were declared normal, $14.15 \%(n=101)$ had definite pathology and $29.55 \%$ ( $n=211$ ) remained undetermined (as they failed to re-produce their histology report at the final step of secondary screening). This study found a bottleneck caused by present service delivery systems; lack of prompt referring and re-reporting to primary center within a schedule time (after receiving management) and lack of recall system both from primary and secondary screening center. To make the program successful have to have schedule for re-reporting and recalling.
\end{abstract}

Key words: cervical cancer, screening, bottleneck.

(Bangladesh J Physiol Pharmacol 2014;30(1):25-28.)

\section{INTRODUCTION}

Cancer cervix (ca cx) continues to be a major problem in many countries, particularly Indian sub continent. $^{1}$ In Bangladesh the yearly burden of carcinoma cervix are about $67,686 .^{2}$ Every year an estimated 1300 women are diagnosed with carcinoma cervix and 6600 die from the disease in each year. ${ }^{3}$

Some of the world-leading research demonstrating, feasible and cost-effective approaches for cervical cancer screening and prevention in low and mediumresource countries is VIA followed by colposcopy ${ }^{4}$; as such in Bangladesh. Very recent publications also support that VIA an easy testing procedure, can be used alone as a cervical cancer screening strategy in a low resource country. ${ }^{5,6}$

Address of Correspondence: Dr. Nasreen Banu, Assistant Professor, Department of Gynaecology \& Obstetrics, $\mathrm{CMCH}$. emaildrnasreenb@yahoo.com
Population based cervical cancer screening was launched in Bangladesh since 2004. ${ }^{7}$ Few countries in the world that have introduced VIA as the primary screening test in a nationwide community based screening program; Bangladesh is one of them. The program is largely opportunistic with good central coordination by Bangabandhu Sheikh Mujib Medical University (BSMMU), Dhaka. BSMMU acts as a training centre (to train family welfare visitors, Nurses and doctors); also as primary screening centre and referral center. Medical colleges (14) act as a primary as well as referral center. Consultants conduct screening, detection and treatment of $\mathrm{ca} \mathrm{cx}$ precursors at secondary and tertiary level of health care. Women above 29 yrs and those who are married before 18 years are included at 25 years of age for screening up to 65 years of age. With a total population of 124 million it is a middle income country. VIA is performed at Medical college Hospitals (14), Maternity \& child welfare centers (61), District Hospitals (57), Upazilla 
health complexes (15 out of 482), Union health \& family welfare centers (44 out of 3725), Urban Primary Health Care Centers (25) and Non Government organizations (NGO 35). ${ }^{2}$

A medical college does VIA and clinical breast examination at OPD by same service provider at $1^{\text {st }}$ visit in the same place. Medical colleges have a separate setup (colposcopy clinic) for referral cases. All VIA positive cases from OPD and different primary screening centers, abnormal pap, positive HPV \& / or suspicious looking cervix are referred in this clinic. Chittagong medical college Hospital $(\mathrm{CMCH})$ is one of them.

Patients in colposcopy clinic diagnose as 'normal' (i.e. normal cervix) / 'pre cancerous lesion' (CIN 1, 2, 3) /'invasive carcinoma'/'others' (benign lesions; infection) etc. Those who are diagnosed as CIN usually offer treatment in the same sitting or in different visit after confirmation of disease through colposcopy guided biopsy. Loop electrosurgical procedure (LEEP) is an excision surgical procedure for CIN that enables simultaneous histological diagnosis and treatment of cervical precancerous lesions and thus eliminating the need for a cervical punch biopsy and an additional visit. $^{5}$

\section{MATERIALS AND METHODS}

This study audited one year cervical cancer screening (April'13 to March'14). A total of 1853 cases from primary screening and 714 cases from secondary screening respectively were included. At OPD most of the subjects were included as opportunistic screening; a few were referred from specialized chambers/ private hospital or willing to do it by themselves.

According to national program for cervical cancer screening VIA done by trained nurses and documented each case as VIA positive (VIA +), VIA negative (VIA-) or suspicious. The positive cases have a red card and all others blue card. The cases either VIA+ or abnormal cytology or positive HPV (as single test or as a sequence of test; i.e more than one test) or suspicious looking are referred for colposcopic evaluation.

In referral center, initially a brief history is taken and than colposcopy is done step wise; $1^{\text {st }}$ step: colposcopic view of cervix and vagina; $2^{\text {nd }}$ step: green filter view to see abnormal vascularity; $3^{\text {rd }}$ step: VIA test; $4^{\text {th }}$ step: VILI test (visual inspection with lugol's iodine); $5^{\text {th }}$ step:( if necessary) LEEP or punch biopsy.

In our setting LEEP is carried out as only treatment procedure for pre-cancerous lesion of the cervix. Most of the time this treatment procedure is carried out on the basis of colposcopic diagnosis in the same visit (see $\&$ treat policy). Sometimes it is done on the basis of histopathology report (punch biopsy) in a separate visit; then it involves 3 visits [1st a screening visit, a 2nd visit for colposcopy and directed biopsy and the 3rd visit for treatment of confirmed CIN cases]. Both the services are going side by side.

Every case is registered in colposcopy register by the colposcopist herself (senior trained doctors) with a diagram, a note of lesion and a definite diagnosis. Diagnosis are pre-cancerous lesion (CIN 1, 2, 3), Carcinoma cervix (ca cx), normal (no lesion found), unsatisfactory (inconclusive), others (benign lesions e.g. polyp, infection etc.).

CIN cases are mostly managed by LEEP after counseling with verbal consent. Patients are asked to produce their histopathology reports (tissues collected either by punch or by LEEP). Histopathology usually sends to pathology department of $\mathrm{CMCH}$ (though not mandatory).

In this study, all the data were extracted from (OPD) 'VIA register' and from (Colposcopy clinic) 'Colposcopy register' during the study period (April'13 to March'14). All the data were analyzed manually.

\section{RESULTS}

In OPD study population were 1853 (as primary screening). Age of the population ranged between 16 to 71 years (maximum 30-49 years). Test positive cases were $118(6.36 \%)$ [Table-I].

Table-I: Primary screening [Population of OPD]

\begin{tabular}{lcc}
\hline Category & $\mathbf{n}$ & \% \\
\hline VIA+ & 118 & $06.36 \%$ \\
\hline VIA- & 1737 & $93.73 \%$ \\
\hline Total & $\mathbf{1 8 5 3}$ & $\mathbf{1 0 0 \%}$ \\
\hline
\end{tabular}

Table-II: Secondary screening [Population of colposcopy clinic]

\begin{tabular}{lcc}
\hline Category & $\mathbf{n}$ & $\mathbf{\%}$ \\
\hline Normal colposcopy & 402 & $56.30 \%$ \\
\hline Abnormal colposcopy & 312 & $43.70 \%$ \\
\hline Total & $\mathbf{7 1 4}$ & $\mathbf{1 0 0 \%}$ \\
\hline
\end{tabular}


Table-III: Colposcopic diagnosis

\begin{tabular}{lcc}
\hline Abnormal & \multicolumn{1}{c}{$\mathbf{n}$} & \% \\
\hline CIN 1 & 134 & 18.77 \\
\hline CIN 2/3 & $\begin{array}{l}120+16 \\
=136\end{array}$ & $\begin{array}{l}16.81+2.24 \\
=19.05\end{array}$ \\
\hline Ca Cx & 270 & $37.81 \%$ \\
\hline Inconclusive & 11 & 01.54 \\
\hline Total & 31 & 04.34 \\
\hline
\end{tabular}

Table-IV: Patient management (after colposcopy)

\begin{tabular}{lcl}
\hline Category & n & percent \\
\hline Tissue sent & 312 & $\mathbf{4 3 . 6 9 \%}$ \\
\hline *LEEP & 67 & $09.38 \%$ \\
\hline $\begin{array}{l}\text { Punch biopsy } \\
\text { Histopathology reports } \\
\text { available }\end{array}$ & 101 & $14.14 \%$ \\
\hline $\begin{array}{l}\text { Histopathology reports not } \\
\text { available }\end{array}$ & 211 & $29.55 \%$ \\
\hline CIN & 86 & $12.04 \%$ \\
\hline Ca CX & 15 & $02.10 \%$ \\
\hline
\end{tabular}

*-patient received definitive treatment.

This study is concentrated on bottlenecks of our service delivery systems at the verge of final management [Table- IV].

Result showed a fairly large number of women (211; $n=29.33 \%$ ) dropped out from final stage of ca cx screening.

\section{DISCUSSION}

Our long term ambition is to reduce the incidence of an eminently preventable disease ca cx. We have to improve ourselves both in skill and service delivery systems. For detailing the understanding of service delivery systems, this study was auditing the ca cx screening program of $\mathrm{CMCH}$, Bangladesh.

VIA is a simple and affordable screening test with acceptable sensitivity and specificity in the range 56$77 \%$ and $64-86 \%$, respectively, in a research setting. ${ }^{8,9}$ A population-based study conducted in Bangladesh observed that the sensitivity and the specificity of VIA performed by trained paramedics were $79 \%$ and $4 \%$, respectively. ${ }^{3}$ The studies performed across the world observed that the range of VIA positivity is $5-9 \%$ in the general population ${ }^{10}$ In Bangladesh overall, $4.7 \%$ of all the screened women tested positive on VIA and the positivity remained almost the same over the last 4 years. $^{3}$ Our VIA positivity is close to both the national ${ }^{2}$ and international ${ }^{10}$ values $(6.38 \%)$.

Very recent publication reported that the approach with 'screen-and-treat' eliminates investigations to confirm a diagnosis prior to treatment and minimizes loss to follow up, delay in treatment and missed disease. A major concern with 'screen-and-treat' cervical cancer prevention strategies is that a large number of women without precursor lesions will undergo treatment; although there are no data to suggest that over treatment is harmfui. ${ }^{5}$

Ca cx screening is a step up program (once primary test is +ve, than go for secondary test; if secondary test is positive than go for investigation and/or treatment; final diagnosis with histopathology). Population of this study had both types of management (two steps and/or three steps).

Present study tried to identify the bottlenecks of the ongoing screening program. There is currently no system for contacting with the screened cases to check whether they have undergone further investigation or not. Also there is no time limit to attend the referral centre. All screened positive cases are not reporting. Re-reporting to primary centre by the subject herself is absent in the existing system. So, a fairly good number of cases don't attend referral centre in spite of test positivity. Again there is no mandatory time limit to reproduce the histopathology report to Colposcopy Clinic. Many a times patients fail to re-produce the histopathology report to referral centre; thereby miss final diagnosis \&/or management.

This study found a fairly large number of screened populations (29.88\%) were dropped out at the verge of final diagnosis.

\section{CONCLUSION}

The authors of this study want to draw the attention of policy makers to generate re-calling system within a framed time limit; only than the present bottleneck of ca cx screening could be overcome.

\section{REFERENCES}

1. Moor MA, Tajimark. Cervical cancer in the asia pacific epidemiology, screening and treatment. Asian Pac J Cancer Prev. 2004; 5(4): 349-361.

2. Nessa A, Hossain MA, Harun-ur- Rashid M, Ahkter N, Roy JS, Afroza R. Role of print and Audiovisual Media in Cervical cancer Prevention in Bangladesh. Asian Pacific J Cancer Prev 2013; 14(5): 3131- 3137 
3. Basu P, Nessa A, Majid M, Rahman JB, Ahmed T. Evaluation of the National Cervical Cancer Screening Programme of Bangladesh and the formulation of quality assurance guidelines. J Fam Plann Reprod Health Care 2010; 36(3): 131-134

4. Sankaranarayanan R. 'See-and-treat' works for cervical cance prevention: what about controlling the high burden in India? Indian J Med Res 2012; 135: 576-579.

5. Huchko MJ, Sneden J, Leslie $\mathrm{HH}$, Abdulrahim N, Maloba M, Bukushi $\mathrm{E}$ et al. A comparison of two visual inspection methodsfor cervical cancer screening among HIV-infected women in Kenya. Bull World Health Organ 2014; 92(3): 195-203.

6. Zhong $Y Z, M a ~ J F$, Zhao FH, Xiang XE, Ma ZH, Shi YT et al. Three year follow-up results of visual inspection with acetic acid/ lugol's iodine (VIA/VILI) used as a alternative screening method for $\mathrm{CX} \mathrm{ca}$ in rural areas. Chin J Cancer 2010; 29(1):4-8.

7. Ahmed T, Ashrafunnessa KS, Rahman J. Development of a Visua Inspection Programme for Cervical Cancer Prevention in Bangladesh. Reproductive Health Matters 2008; 16: 78-85.

8. Sankaranarayanan R, Basu P, Wesley RS, Mahe C, Keita N,Mbalawa CC, et al. IARC Multicentre Study Group on Cervical Cancer Early Detection. Accuracy of visual screening for cervical neoplasia: results from an IARC Multicentre Study in India and Africa. Int J Cancer 2004; 110: 907-913.

9. Sankaranarayanan $R$, Esmy $P O$, Rajkumar $R$, Muwonge $R$, Swaminathan R, Shanthakumari S, et al. Effect of visual screening on cervical cancer incidence and mortality in Tamil Nadu, India: a cluster-randomised trial. Lancet 2007; 370: 398-406.

10. Basu $P$, Majid M. Cervical cancer screening program of Bangladesh: Evaluation and formulation of quality assurance, standards \& guideline. UNFPA, Bangladesh June 2008. 